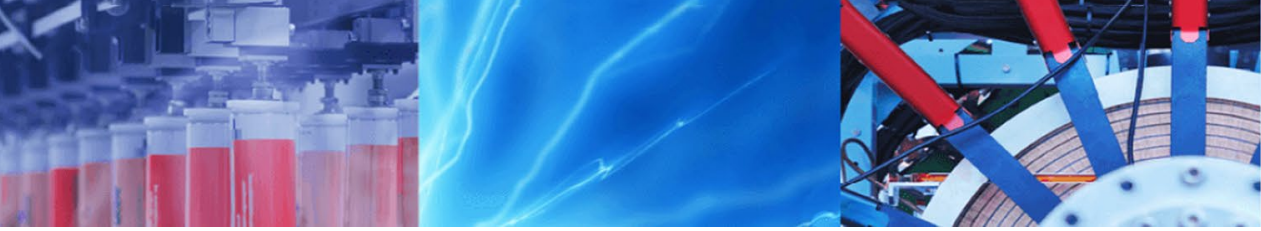

Research Article

\title{
Preparation and characterization of magnetic zirconium oxide nanocomposite as a catalyst for reduction of methylene blue
}

\author{
Mehdi Gheisari Goudarzi ${ }^{1} \cdot$ Mojtaba Bagherzadeh $^{2} \mathbb{D} \cdot$ Fatemeh Taheri $^{2} \cdot$ Akbar Rostami-Vartooni $^{3}$
}

Received: 29 February 2020 / Accepted: 10 June 2020 / Published online: 19 June 2020

(c) Springer Nature Switzerland AG 2020

\begin{abstract}
In this work, magnetic zirconium oxide $\left(\mathrm{ZrO}_{2} / \mathrm{Fe}_{3} \mathrm{O}_{4}\right)$ nanocomposites were synthesized in different mass ratio as $(1: 1)$, (3:2), (5:2) and (7:2) and fairly characterized by various techniques like; $X$-ray diffraction, $X$-ray energy dispersion analysis, scanning electron microscope, transmission electron microscopy, Fourier transform infrared spectroscopy, and vibrating sample magnetometer. Characterization results showed the prepared nanocomposite had stable core/shell structure in nanometer scale, $12 \mathrm{~nm}$, with magnetically property that nominate it for catalytic application in chemical reactions. The prepared nanocomposites were evaluated in the reduction reaction of methylene blue and in the presence of $\mathrm{NaBH}_{4}$ as a catalyst. Observed results revealed that the $\mathrm{ZrO}_{2} / \mathrm{Fe}_{3} \mathrm{O}_{4}$ nanocomposites in mass ratio as 5:2 exhibited remarkable catalytic activity with excellent reusability. Obtained results are presented and discussed here.
\end{abstract}

Keywords $\mathrm{ZrO}_{2} / \mathrm{Fe}_{3} \mathrm{O}_{4}$ nanocomposite $\cdot$ Superparamagnetic $\cdot$ Core-shell $\cdot$ Reduction $\cdot$ Methylene blue

\section{Introduction}

The accessible magnetic materials are magnetite $\left(\mathrm{Fe}_{3} \mathrm{O}_{4}\right)$, and it is one of the most studied ferrimagnetic compounds. Due to extensively application of magnetic nanomaterials in various scientific fields like ultrahigh density magnetic storage media [1-3], medicine [4, 5] biological labeling, tracking, imaging, detection, and separations [6], and ferrofluid [7] they have attracted the significant attention in recent years. Due to the negligible energy barrier in the hysteresis of the magnetization loop and noticeably small coercivity, magnetite nanoparticles with size below $26 \mathrm{~nm}$ exhibit superparamagnetic behavior $[8,9]$. Consequently, nanoscale materials and magnetite have been intensively studied recently in diagnostic, biomedical, and removal or separation of hazardous materials [10-15]. For the end goal, the magnetite nanoparticles act as a catalyst or supporter in reduction or oxidation of dangerous many dyes and easily separated from the solution reaction by using a magnetic field [16-18].

3,7-Bis (dimethylamino)-phenothiazin-5-ium chloride, known as methylene blue (MB), is one of the famous harmful pollutants and has detrimental effects on human health [19]. To convert this dangerous dye form to suitable products, many strategies like photochemical and biological degradation, oxidation, and reduction, have been reported in recent years. Among them, the catalytic reduction of blue color $\mathrm{MB}$ into colorless reduced form (leucomethylene blue, LB) is considered more preferable. $\mathrm{LB}$ is the counterpart of $M B$ and has numerous applications in various industrial fields. However, this reduction reaction is the kinetically unfavorable reaction. Consequently, different catalytic systems utilized based on nanomaterials to speeding up this specific reaction [19].

Herein, magnetite $\left(\mathrm{Fe}_{3} \mathrm{O}_{4}\right)$ nanoparticles were used as a supporter for the immobilizing of the $\mathrm{ZrO}_{2}$ on them to

$\triangle$ Mehdi Gheisari Goudarzi, gheisarime@gmail.com; $₫$ Mojtaba Bagherzadeh, mjmo123@yahoo.com; mbagherzadeh@aeoi.org.ir| ${ }^{1}$ Department of Physics, Aligudarz Branch, Islamic Azad University, Aligudarz, Islamic Republic of Iran. ${ }^{2}$ Reactor and Nuclear Safety School, Nuclear Science and Technology Research Institute, 81465-1589, Isfahan, Islamic Republic of Iran. ${ }^{3}$ Department of Chemistry, Faculty of Science, University of Qom, Qom 3716146611, Islamic Republic of Iran. 
synthesize magnetic zirconium oxide nanocomposites. The mass ratio of the $\mathrm{ZrO}_{2}$ to $\mathrm{Fe}_{3} \mathrm{O}_{4}$ was changed to control the magnetization and catalytic activity. The prepared nanocomposite was characterized, and its catalytic activity in the reduction of MB was investigated. Observed results are presented and discussed.

\section{Experimental and processer}

\subsection{Materials and instruments}

Doubly distilled de-ionized water (Millipore Milli-Q, France, $18 \mathrm{M} \Omega$ ) was used to preparation of all the solutions. Zirconyl chloride $\left(\mathrm{ZrCl}_{4}\right)$, ferrous chloride $\left(\mathrm{FeCl}_{2} \cdot 4 \mathrm{H}_{2} \mathrm{O}\right)$, ferric chloride $\left(\mathrm{FeCl}_{3} \cdot 6 \mathrm{H}_{2} \mathrm{O}\right)$, methylene blue $(\mathrm{MB})$, and all other chemicals were purchased from Merck . An X-ray diffractometer (Bruker Advanced D8 model), that use $\mathrm{CuK}_{a}$ radiation $\left(\lambda=1.5406 \mathrm{~A}^{\circ}\right)$, was used for crystal structure study of the prepared powders. A Perkin Elmer Spectrum Version 10.00.00 was used for Fourier transform infrared (FTIR) spectra recording. A scanning electron microscope (SEM) equipped with EDXA (Philips XL-30) was used for morphology and elemental analysis of the samples. The transmission electron microscope, TEM (Philips-EM-208S), was used for the size measurement of the prepared nanocomposites. Vibrating sample magnetometer (VSM, Daghigh Meghnatis Kashan Co., Kashan, Iran) was used for magnetic measurements at room temperature. And finally, a double-beam UV-Vis spectrophotometer (Cintra 404) was used for monitoring the reduction reactions of MB dye.

\subsection{Preparation of magnetic zirconium oxide nanocomposites}

The magnetic zirconium oxide nanocomposites were synthesized via chemical co-precipitation methods. $25 \mathrm{~mL}$ of $\mathrm{HCl}(1 \mathrm{M})$ was deaerated with $\mathrm{N}_{2}$ gas for 20 min, then $\mathrm{FeCl}_{3} \cdot 6 \mathrm{H}_{2} \mathrm{O}$ and $\mathrm{FeCl}_{2} \cdot 4 \mathrm{H}_{2} \mathrm{O}$ in ratio as $2: 1$ were added to it. $250 \mathrm{~mL}$ of $1.5 \mathrm{M} \mathrm{NaOH}$ solution at $80^{\circ} \mathrm{C}$ was prepared and then, the $\mathrm{HCl}$ solution was added dropwise into it under vigorous stirring. A permanent magnet was used to separate obtained magnetic nanoparticles $\left(\mathrm{Fe}_{3} \mathrm{O}_{4}\right)$ from the reaction medium. Prepared $\mathrm{Fe}_{3} \mathrm{O}_{4}$ washed with $200 \mathrm{~mL}$ deionized water four times. For coating, the $\mathrm{ZrO}_{2}$ on the prepared $\mathrm{Fe}_{3} \mathrm{O}_{4}, 1 \mathrm{M}$ solution of $\mathrm{ZrCl}_{4}$ in $\mathrm{HClO}_{4}$ was added dropwise into the suspension of $\mathrm{Fe}_{3} \mathrm{O}_{4}$ nanoparticles. By addition of $2 \mathrm{M} \mathrm{NaOH}$ within one $\mathrm{h}$, the $\mathrm{pH}$ was adjusted to 8.0, at $80^{\circ} \mathrm{C}$, under $\mathrm{N}_{2}$ gas, and stirred for two h. By varying the proportion of precipitated $\mathrm{ZrO}_{2}$ on $\mathrm{Fe}_{3} \mathrm{O}_{4}$ nanoparticles suspension, the mass ratio of $\mathrm{ZrO}_{2}$ to $\mathrm{Fe}_{3} \mathrm{O}_{4}$ adjusted to $1: 1,3: 2,5: 2$, and $7: 2$. Finally, the prepared nanocomposites were thoroughly washed with deionized water.

\subsection{Catalytic reduction of MB}

For investigation of catalytic activity of prepared nanocomposites, $50 \mathrm{~mL}$ aqueous $\mathrm{NaBH}_{4}$ solution $\left(5.3 \times 10^{-3} \mathrm{M}\right)$ was added to $50 \mathrm{ml}$ of $\mathrm{MB}$ azo dye (10 ppm) and $7 \mathrm{mg}$ magnetic zirconium oxide nanocomposites were dispersed in it mixture solution. The solution mixture was stirred at room temperature, and then the concentration of MB in solution was monitored by UV-Vis spectrophotometer at $\lambda_{\max }$ of $665 \mathrm{~nm}$.

\section{Results and discussion}

\subsection{Characterization of magnetic nanocomposite catalyst}

The XRD patterns of prepared $\mathrm{Fe}_{3} \mathrm{O}_{4}$ and $\mathrm{ZrO}_{2} / \mathrm{Fe}_{3} \mathrm{O}_{4}$ nanocomposite presented in Fig. 1. As can be seen, the planes (111), (200), (220), and (311) of $\mathrm{ZrO}_{2}$ are observed at $2 \theta 30.4,35.2,50.6$, and $60.3^{\circ}$ in the pattern (c), respectively. Furthermore, the planes (220), (311), (400), (511), and (440) of magnetite $\left(\mathrm{Fe}_{3} \mathrm{O}_{4}\right)$ are observed at $2 \theta$ 30.0, $35.5,43.5,57.2$, and $62.7^{\circ}$ in the pattern $(b)$, in which demonstrated the high purity $\mathrm{Fe}_{3} \mathrm{O}_{4}$ spinel structure was synthesized. Comparison of the XRD pattern (a) with patterns $(b$ and $c)$ in Fig. 1, proved the existence of zirconia in the resulting composite that marked in pattern (a). Finally, by using the Scherrer's formula, the average crystallite size as $12 \pm 1 \mathrm{~nm}$ was calculated from the broadening of XRD peaks [20].

The composition of the prepared nanocomposite was further analyzed by using the X-ray energy dispersion analysis (EDXA), Fig. 2a. Elemental analysis (Fig. 2, inset) showed the main elements in the composite were iron, oxygen and zirconium that confirmed preparation of $\mathrm{ZrO}_{2} / \mathrm{Fe}_{3} \mathrm{O}_{4}$ nanocomposite successfully. For comparison the SEM image and related EDX analysis of $\mathrm{ZrO}_{2}$ presented in Fig. 2b. The actual size and shape of the prepared nanocomposite were analyzed by using TEM imaging (Fig. 2c, d). As can be seen, the prepared composite had spherical in form and tendency to agglomeration. The TEM image in Fig. 2c showed a core/shell structure for prepared $\mathrm{ZrO}_{2} / \mathrm{Fe}_{3} \mathrm{O}_{4}$ nanocomposite in around the crystallite size calculated by using Scherrer's formula $(12 \mathrm{~nm})$. The SAED image obtained from the edge and the center of one of the spherical, non-agglomerated $\mathrm{ZrO}_{2} / \mathrm{Fe}_{3} \mathrm{O}_{4}$ nanocomposite, Fig. 2e. As can be see, when traversed from the edge towards the center of the particle, a number of diffraction spots are observed in the SAED pattern of the $\mathrm{ZrO}_{2} / \mathrm{Fe}_{3} \mathrm{O}_{4}$ nanoparticle. This 


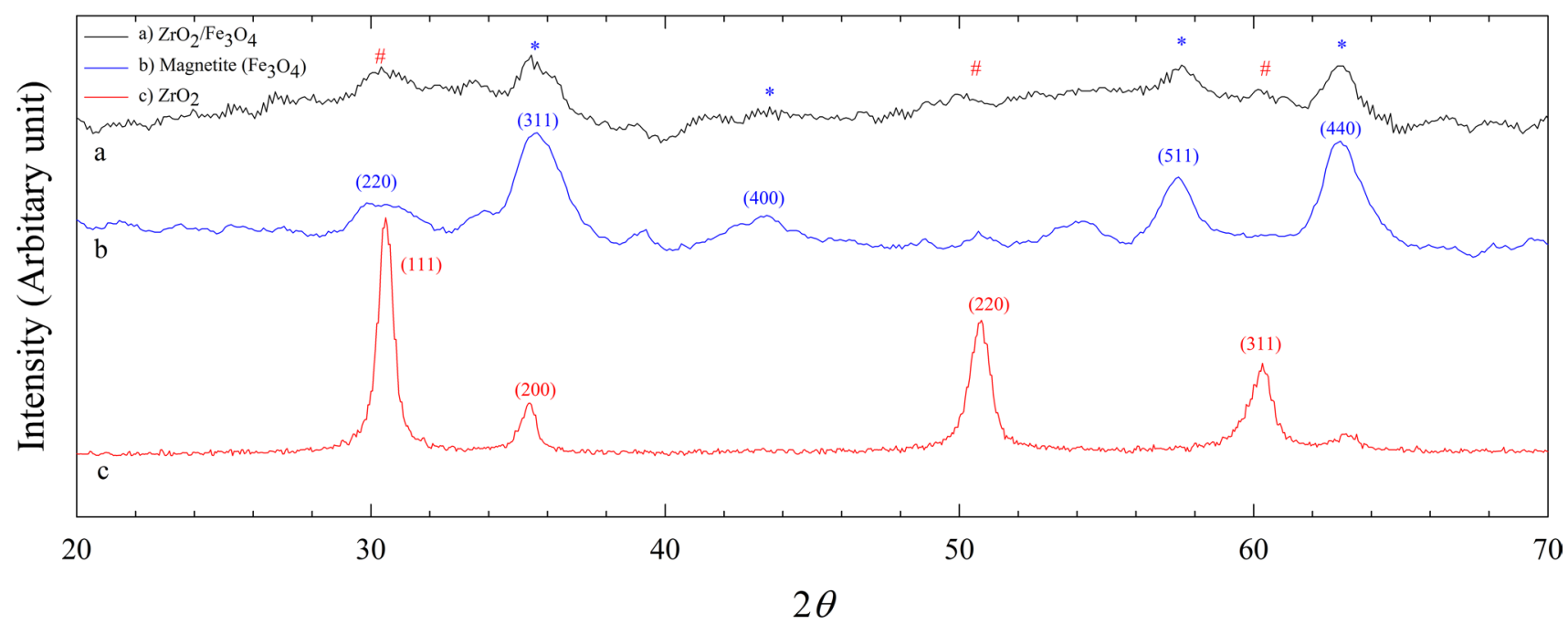

Fig. 1 The typical XRD patterns of the as-prepared $\mathrm{ZrO}_{2} / \mathrm{Fe}_{3} \mathrm{O}_{4}$ nanocomposite (a), $\mathrm{Fe}_{3} \mathrm{O}_{4}$ (b), and $\mathrm{ZrO}_{2}$ (c)

indicates that a large number of nanocrystallites related to $\mathrm{ZrO}_{2}$, as a shell, are located at the edge of the core particle, $\mathrm{Fe}_{3} \mathrm{O}_{4}$.

Figure $3 \mathrm{~A}$ shows the FTIR spectrum of the $\mathrm{ZrO}_{2} / \mathrm{Fe}_{3} \mathrm{O}_{4}$ $(5: 2)$ nanocomposite. As can be seen, the characteristic bands at $500-850 \mathrm{~cm}^{-1}$, which is due to the $\mathrm{Zr}-\mathrm{O}$ bond, of zirconia were observed in the FTIR spectrum [21]. Found evidence related to surface functional groups of prepared nanocomposite proved successful synthesis of magnetic zirconium oxide.

Figure $3 \mathrm{~B}$ shows the vibrating sample magnetometer (VSM) analysis of the prepared nanocomposites with different mass ratios of $\mathrm{ZrO}_{2}$ to $\mathrm{Fe}_{3} \mathrm{O}_{4}$. As can be seen, all of the nanocomposites showed the typically superparamagnetic behavior, no coercivity, remanence, and hysteresis. However, in the application of magnetic materials, the saturation magnetization is a critical factor in effective magnetic separation. $\mathrm{ZrO}_{2}$ is a nonmagnetic material, and increasing the mass ratio of it led to decreasing the magnetic strength of resulting nanocomposite. As can be seen from Table 1, the saturation magnetization of prepared nanocomposites decreased by increasing the $\mathrm{ZrO}_{2}$ amount. The core-shell coupling model was used to explain the observed behavior [22]. It is the assumption that each particle consists of $\mathrm{Fe}_{3} \mathrm{O}_{4}$ core that coated by a constant thickness nonmagnetic shell of $\mathrm{ZrO}_{2}$. According to this model, the non-magnetic coating layer $\left(\mathrm{ZrO}_{2}\right)$ make a disordering on the magnetic moment of surface and forms a magnetic dead layer on the surface of $\mathrm{Fe}_{3} \mathrm{O}_{4}$ nanoparticles, that cause to decreasing the magnitude of the magnetization via quenching the surface moment [23]. Based on the core-shell model, and also in agreement by HRTEM image (Fig. 2b inset), due to the spherical form of particles, the magnetization is given by this equation:
$M=M_{0}[(D-2 t) / D]^{3}$

where $M_{0}, D$, and $t$ are the magnetization of $\mathrm{Fe}_{3} \mathrm{O}_{4}$, the diameter of whole core-shell particle $\left(\mathrm{ZrO}_{2} / \mathrm{Fe}_{3} \mathrm{O}_{4}\right)$, and thickness of the died layer $\left(\mathrm{ZrO}_{2}\right)$, respectively. Based on existing relationship and XRD, TEM results $(D=12 \mathrm{~nm})$, the depth of the non-magnetic layer $t$ of $\mathrm{ZrO}_{2} / \mathrm{Fe}_{3} \mathrm{O}_{4} ;(1: 1)$, (3:2), (5:2) and (7:2) were calculated as shown at Table 1.

We found that the magnetization value for $\mathrm{ZrO}_{2} / \mathrm{Fe}_{3} \mathrm{O}_{4}$ (5:2) nanocomposite is enough for magnetic separation with a conventional permanent magnet (Fig. $3 \mathrm{~A}$ inset). Also, the thickness of the sample shell is suitable for our future studies in catalytic studies.

\subsection{Application of the $\mathrm{ZrO}_{2} / \mathrm{Fe}_{3} \mathrm{O}_{4}$ for the reduction of MB dye}

The reduction reaction of $\mathrm{MB}$ azo dye in the presence of $\mathrm{NaBH}_{4}$ and $\mathrm{ZrO}_{2} / \mathrm{Fe}_{3} \mathrm{O}_{4}$ nanocomposite was selected to the evaluation of the catalytic activity of prepared nanocomposite. In this process, the blue color solution of MB change to a completely colorless solution. Of course, the original color of solution can return during 1.5 and $4 \mathrm{~h}$ in the presence of the $\mathrm{ZrO}_{2} / \mathrm{Fe}_{3} \mathrm{O}_{4}$ nanocomposite. Figure 4 shows the changes in the absorption band of $\mathrm{MB}$ in the presence of the $\mathrm{ZrO}_{2} / \mathrm{Fe}_{3} \mathrm{O}_{4}$ nanocomposite during catalytic reduction. In addition, the reduction times of $\mathrm{MB}$ dye in the presence of $\mathrm{Fe}_{3} \mathrm{O}_{4}$ and its nanocomposite are summarized in Table 2. The results revealed that the $\mathrm{ZrO}_{2} /$ $\mathrm{Fe}_{3} \mathrm{O}_{4}$ nanocomposite in weight ratio as $5: 2$ showed the best catalytic performance. This catalytic behavior is due to facilitate the electron transfer from $\mathrm{BH}_{4}{ }^{-}$to the $\mathrm{MB}$ dye in the reduction process on the surface of the $\mathrm{ZrO}_{2} / \mathrm{Fe}_{3} \mathrm{O}_{4}$ nanocomposite. 

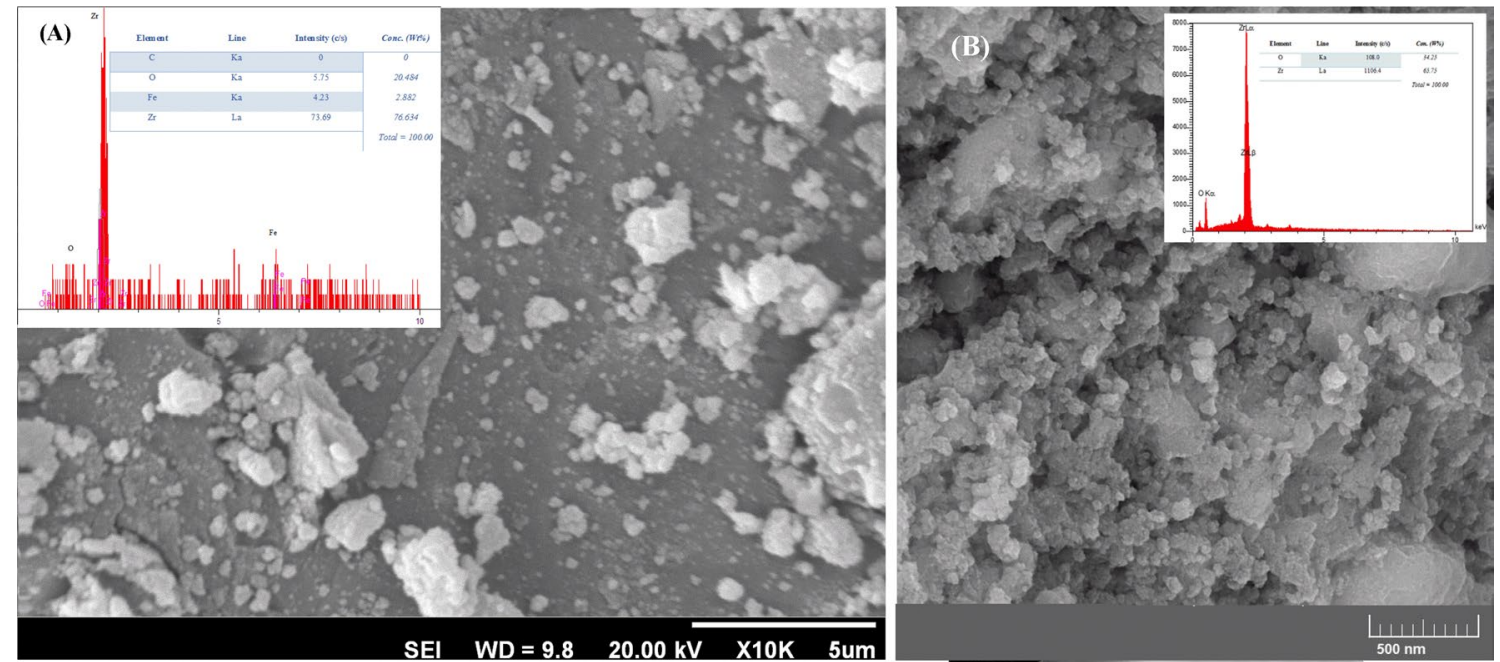

(C)
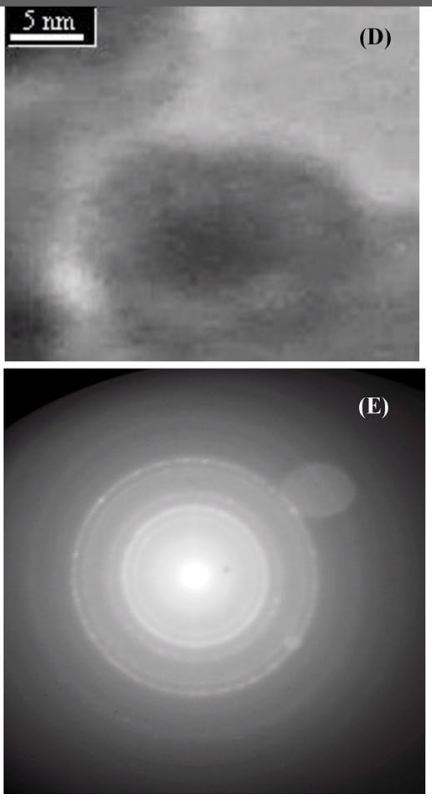

Fig. 2 a The SEM image of the prepared $\mathrm{ZrO}_{2} / \mathrm{Fe}_{3} \mathrm{O}_{4}$ nanocomposite and corresponding EDX analysis results (inset). $\mathbf{b}$ The SEM image of the prepared $\mathrm{ZrO}_{2}$ nanoparticles and corresponding EDX analysis results (inset). $\mathbf{c}$, $\mathbf{d}$ The TEM images of the prepared $\mathrm{ZrO}_{2} / \mathrm{Fe}_{3} \mathrm{O}_{4}$

As can be concluded from data in Table 2, the catalytic activity of the prepared $\mathrm{ZrO}_{2} / \mathrm{Fe}_{3} \mathrm{O}_{4}$ nanocomposite for the reduction of $\mathrm{MB}$ is comparable with previously reported catalysts $[19,24-26]$.

\subsection{Catalytic mechanism}

Our literature survey show, that most researchers used the typical Langmuir-Hinshelwood model for the reduction of $\mathrm{MB}$ in the presence of reductants at nanocatalysts surface $[30,31]$. In the present work, this mechanism can be applied and schematically illustrated in Scheme 1. Based on this mechanism both $\mathrm{MB}$ and $\mathrm{NaBH}_{4}$, were adsorbed nanocomposite. The scale bars are $40 \mathrm{~nm}$, and $5 \mathrm{~nm}$ in $\mathbf{c}, \mathbf{d}$, respectively. e The SAED image obtained from the $\mathrm{ZrO}_{2} / \mathrm{Fe}_{3} \mathrm{O}_{4}$ nanocomposite

onto the surface of $\mathrm{ZrO}_{2} / \mathrm{Fe}_{3} \mathrm{O}_{4}$ nanocomposite. Adsorption of $\mathrm{NaBH}_{4}$ and $\mathrm{MB}$ molecules over the surface of $\mathrm{ZrO}_{2} /$ $\mathrm{Fe}_{3} \mathrm{O}_{4}$ nanocomposite occur via two manners, direct absorption and hydrogen bonding-assisted absorption. These adsorptions are rapid and reversible in nature. Apart from the physical adsorption, hydrogen bonding plays an important role in attaching the MB molecules onto the surface of $\mathrm{ZrO}_{2} / \mathrm{Fe}_{3} \mathrm{O}_{4}$. Oxygen functional groups bonded to $\mathrm{Zr}$ and $\mathrm{Fe}$ atoms in $\mathrm{ZrO}_{2} / \mathrm{Fe}_{3} \mathrm{O}_{4}$ nanocomposite are more favorable for hydrogen bonding. Adsorbed borohydride ions $\left(\mathrm{BH}_{4}^{-1}\right)$ release hydrogen on $\mathrm{ZrO}_{2} / \mathrm{Fe}_{3} \mathrm{O}_{4}$ surface, which also generally helps in the adsorption of $\mathrm{MB}$ by forming catalyst-H complexes on its surface. After adsorption, MB 

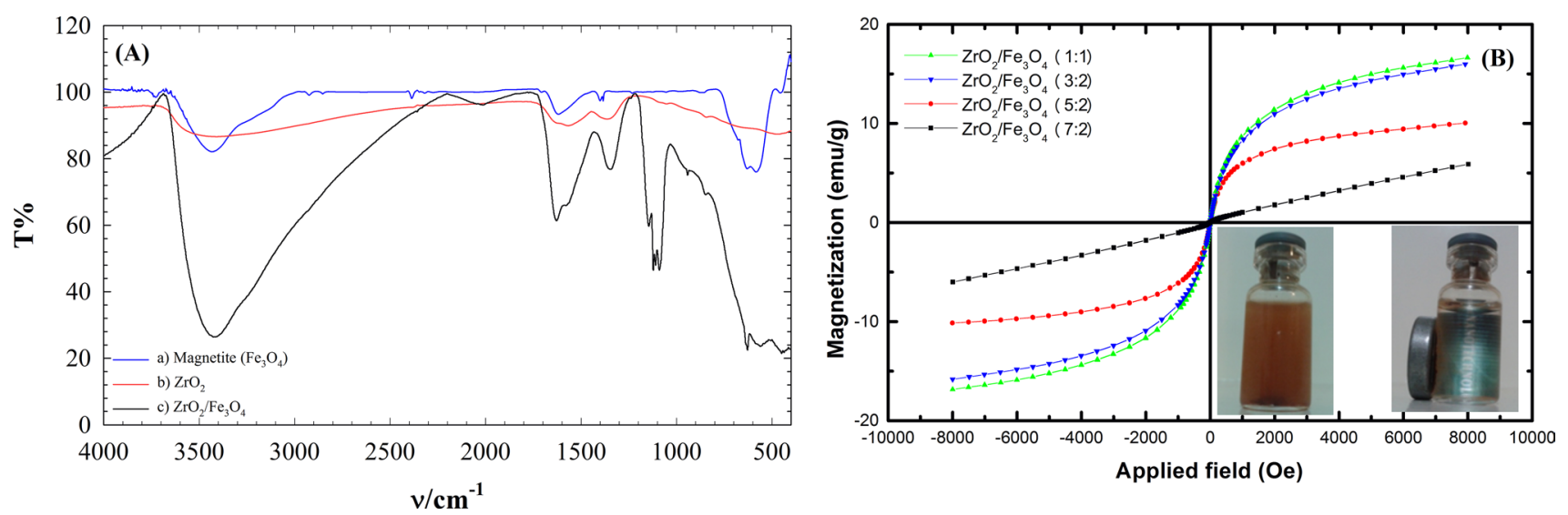

Fig. 3 A The FTIR spectrum of (a) Magnetite $\left(\mathrm{Fe}_{3} \mathrm{O}_{4}\right)$, (b) $\mathrm{ZrO}_{2}$, and (c) $\mathrm{ZrO}_{2} / \mathrm{Fe}_{3} \mathrm{O}_{4}$ (5:2) nanocomposite. B The VSM magnetization curves of $\mathrm{ZrO}_{2} / \mathrm{Fe}_{3} \mathrm{O}_{4}$ nanocomposites at room temperature. Inset is the response of the $\mathrm{ZrO}_{2} / \mathrm{Fe}_{3} \mathrm{O}_{4}(5: 2)$ nanocomposite to a permanent magnet

Table 1 Magnetization (at 75000e) and thicknesses of the nonmagnetic layer $(\mathrm{t})$ of samples

\begin{tabular}{llllll}
\hline & $\mathrm{Fe}_{3} \mathrm{O}_{4}$ & $\begin{array}{l}\mathrm{ZrO}_{2} / \mathrm{Fe}_{3} \mathrm{O}_{4} \\
(1: 1)\end{array}$ & $\begin{array}{l}\mathrm{ZrO}_{2} / \mathrm{Fe}_{3} \mathrm{O}_{4} \\
(3: 2)\end{array}$ & $\begin{array}{l}\mathrm{ZrO}_{2} / \mathrm{Fe}_{3} \mathrm{O}_{4} \\
(5: 2)\end{array}$ & $\begin{array}{l}\mathrm{ZrO}_{2} / \\
\mathrm{Fe}_{3} \mathrm{O}_{4} \\
(7: 2)\end{array}$ \\
\hline $\mathrm{M}(\mathrm{emu} / \mathrm{g})$ & 42.5 & 22.7 & 15.5 & 10.1 & 6.9 \\
$\mathrm{t}(\mathrm{nm})$ & - & 1.1 & 1.7 & 2.3 & 2.7 \\
\hline
\end{tabular}

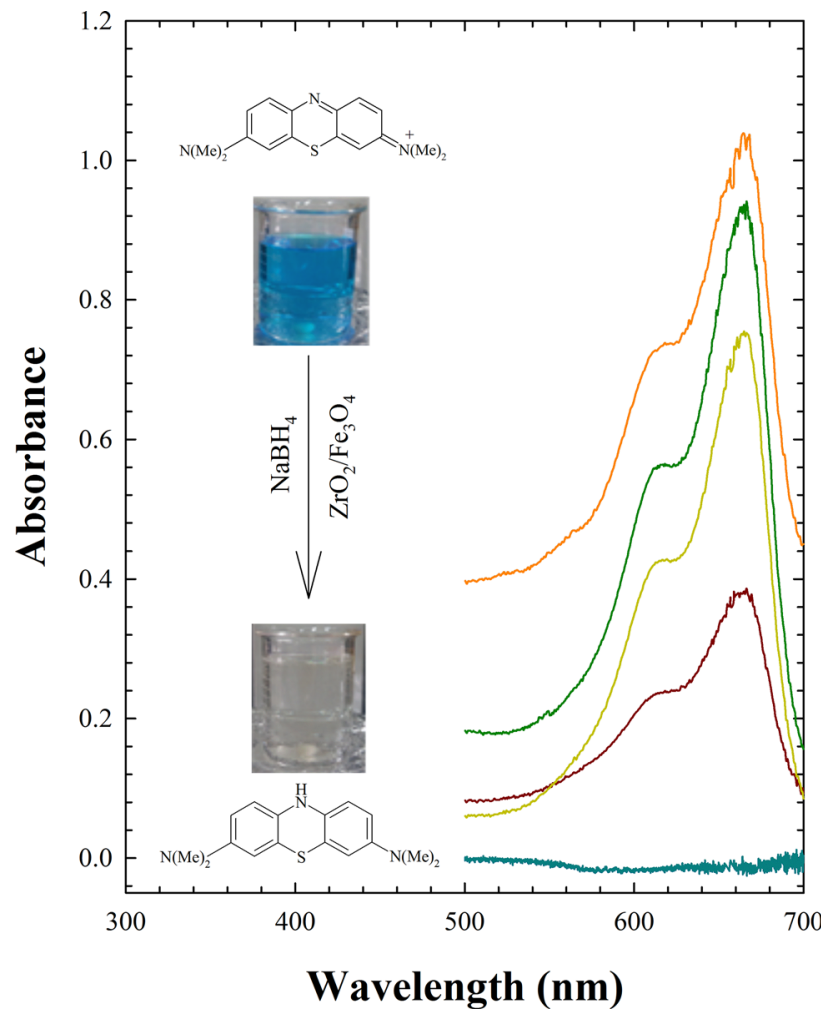

Fig. 4 UV-Vis spectra of MB during the catalytic reduction
Table 2 The reaction time in the reduction of $\mathrm{MB}$ by using $\mathrm{ZrO}_{2} /$ $\mathrm{Fe}_{3} \mathrm{O}_{4}$ nanocomposite in comparison to recent works

\begin{tabular}{lrl}
\hline Type of catalyst & Reaction time/min & $\begin{array}{l}\text { Refer- } \\
\text { ences }\end{array}$ \\
\hline- & 120 & This work \\
$\mathrm{Fe}_{3} \mathrm{O}_{4}$ & 60 & \\
$\mathrm{ZrO}_{2}$ & 35 & \\
$\mathrm{ZrO}_{2} / \mathrm{Fe}_{3} \mathrm{O}_{4}$ & 5 & {$[27]$} \\
$\mathrm{Fe}_{3} \mathrm{O}_{4}-\mathrm{Ag}$ & 18 & {$[28]$} \\
$\mathrm{Fe}_{3} \mathrm{O}_{4} @ \mathrm{HA} @ \mathrm{Ag}$ & 20 & {$[29]$} \\
$\mathrm{Fe}_{3} \mathrm{O}_{4} @ \mathrm{Nico}-\mathrm{Ag}$ & 5 &
\end{tabular}

HA humic acid, Nico nicotinic acid

molecules interact with the adsorbed molecules of $\mathrm{NaBH}_{4}$ on the surface of $\mathrm{ZrO}_{2} / \mathrm{Fe}_{3} \mathrm{O}_{4}$ nanocomposite. $\mathrm{ZrO}_{2} / \mathrm{Fe}_{3} \mathrm{O}_{4}$ nanocomposite acts as an agent that overcomes the kinetic barrier and catalyzes the reaction by facilitating electron transference from the $\mathrm{NaBH}_{4}$ to the MB molecules $[32,33]$. The product formed, $L M B$, desorbs from the surface of the $\mathrm{ZrO}_{2} / \mathrm{Fe}_{3} \mathrm{O}_{4}$ nanocomposite and diffuses from the surface to the bulk region [32].

\subsection{Recyclability of catalyst}

To explore the recyclability of the $\mathrm{ZrO}_{2} / \mathrm{Fe}_{3} \mathrm{O}_{4}$ nanocomposite, it separated from the reaction solution by using a permanent magnet, washed with double distilled water and ethanol, then dried and used up to 3 times in the reduction reaction of $\mathrm{MB}$. Our results showed that the $\mathrm{ZrO}_{2} / \mathrm{Fe}_{3} \mathrm{O}_{4}$ nanocomposite in one, two, three and four catalytic runs showed reaction times as 5, 6, 8, and $10 \mathrm{~min}$ for $100 \%$ reduction of $\mathrm{MB}$, respectively (Fig. 5 ). Consequently, the efficiency of recovered catalysts maintains significantly 


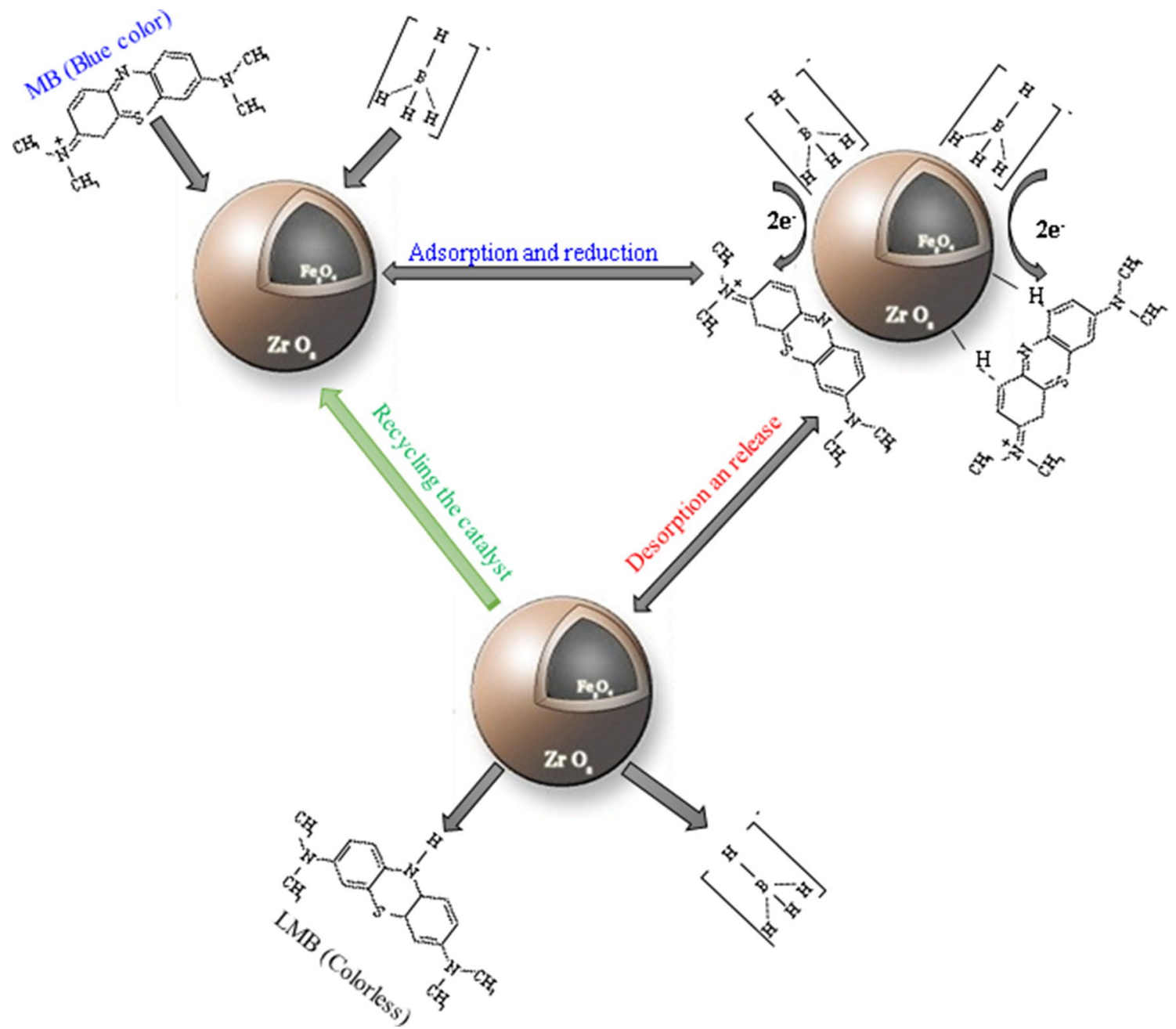

Scheme 1 Possible mechanism of $\mathrm{MB}$ reduction in the presence on $\mathrm{NaBH}_{4}$ at $\mathrm{ZrO}_{2} / \mathrm{Fe}_{3} \mathrm{O}_{4}$ nanocomposite

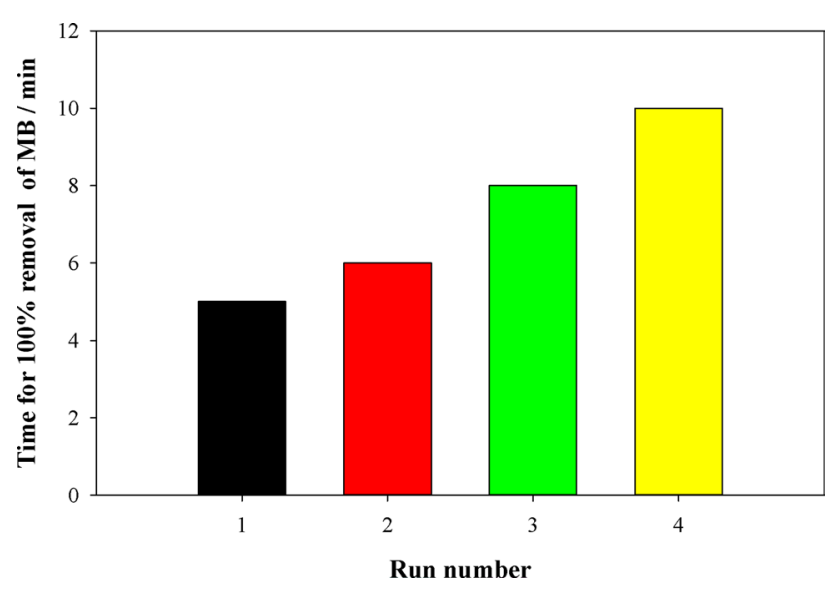

Fig. 5 The recyclability of catalyst during four catalytic runs unchanged, indicating the high stability of the $\mathrm{ZrO}_{2} / \mathrm{Fe}_{3} \mathrm{O}_{4}$ nanocomposite as a catalyst in real applications.

\section{Conclusion}

In this work, the $\mathrm{ZrO}_{2} / \mathrm{Fe}_{3} \mathrm{O}_{4}$ nanocomposites were successfully prepared and characterized by using XRD, SEM, EDXA, TEM, FTIR, and VSM techniques. Based on the dead layer model, by increasing nonmagnetic $\mathrm{ZrO}_{2}$ shell at $\mathrm{Fe}_{3} \mathrm{O}_{4}$ magnetic core, the magnetization of samples decreases. However, the increase of the contribution of $\mathrm{ZrO}_{2}$ in $\mathrm{ZrO}_{2} / \mathrm{Fe}_{3} \mathrm{O}_{4}$ is resulting in the increased catalytic activity of prepared composite. In the processes of filtering or separation, unhealthy materials from wastewater under the external magnetic field, high magnetization, and high catalytic activity are two key factors. According to two parameters: (1) magnetization and (2) thickness of $\mathrm{ZrO}_{2}$, superparamagnetic $\mathrm{ZrO}_{2} / \mathrm{Fe}_{3} \mathrm{O}_{4}(5: 2)$ nanocomposite 
was the best candidate in the catalytic reduction of MB. Prepared nanocatalyst showed good performance in catalytic reduction of $\mathrm{MB}$ in the presence of $\mathrm{NaBH}_{4}$. Therefore, this newly synthesized $\mathrm{ZrO}_{2} / \mathrm{Fe}_{3} \mathrm{O}_{4}$ nanocomposite can be a promising nanocatalyst for the reduction of industrial waste azo dyes like MB during the wastewater treatment.

Acknowledgements The authors acknowledge the deputy of research and technology of Islamic Azad University, Aligudarz branch, and NSTRI for its support of this work.

\section{Compliance with ethical standards}

Conflict of interest The authors declare that they have no conflict of interest.

\section{References}

1. Piekarz P, Parlinski K, Oleś AM (2007) Origin of the Verwey transition in magnetite: group theory, electronic structure, and lattice dynamics study. Phys Rev B 76(16):165124

2. Kobayashi H, Isogai I, Kamimura T, Hamada N, Onodera H, Todo S, Môri N (2006) Structural properties of magnetite under high pressure studied by Mössbauer spectroscopy. Phys Rev B 73(10):104110

3. Zeng H, Li J, Liu JP, Wang ZL, Sun S (2002) Exchange-coupled nanocomposite magnets by nanoparticle self-assembly. Nature 420(6914):395-398

4. Häfeli U, Schütt W, Teller J, Zborowski M (2013) Scientific and clinical applications of magnetic carriers. Springer, New York

5. Weissleder R, Bogdanov A, Neuwelt EA, Papisov M (1995) Longcirculating iron oxides for MR imaging. Adv Drug Deliv Rev 16(2-3):321-334

6. Nam J-M, Thaxton CS, Mirkin CA (2003) Nanoparticle-based biobar codes for the ultrasensitive detection of proteins. Science 301(5641):1884-1886

7. Raj K, Moskowitz R (1990) Commercial applications of ferrofluids. J Magn Magn Mater 85(1-3):233-245

8. Cullity B (1972) Introduction to magnetic materials. AddisonWesley, Reading

9. Lian S, Kang Z, Wang E, Jiang M, Hu C, Xu L (2003) Convenient synthesis of single crystalline magnetic $\mathrm{Fe}_{3} \mathrm{O}_{4}$ nanorods. Solid State Commun 127(9-10):605-608

10. Rao GN, Yao Y, Chen Y, Wu K, Chen J (2005) Particle size and magnetic field-induced optical properties of magnetic fluid nanoparticles. Phys Rev E 72(3):031408

11. Zhao X, Wang J, Wu F, Wang T, Cai Y, Shi Y, Jiang G (2010) Removal of fluoride from aqueous media by $\mathrm{Fe}_{3} \mathrm{O}_{4} @ \mathrm{Al}(\mathrm{OH}) 3$ magnetic nanoparticles. J Hazard Mater 173(1-3):102-109

12. Naghdi S, Sajjadi M, Nasrollahzadeh M, Rhee KY, Sajadi SM, Jaleh B (2018) Cuscuta reflexa leaf extract mediated green synthesis of the Cu nanoparticles on graphene oxide/manganese dioxide nanocomposite and its catalytic activity toward reduction of nitroarenes and organic dyes. JTaiwan Inst Chem Eng 86:158-173

13. Jaleh B, Karami S, Sajjadi M, Mohazzab BF, Azizian S, Nasrollahzadeh M, Varma RS (2020) Laser-assisted preparation of Pd nanoparticles on carbon cloth for the degradation of environmental pollutants in aqueous medium. Chemosphere 246:125755

14. Nasrollahzadeh M, Sajjadi M, Tahsili MR (2020) High efficiency treatment of organic/inorganic pollutants using recyclable magnetic N-heterocyclic copper (II) complex and its antimicrobial applications. Sep Purif Technol 238:116403
15. Maham M, Nasrollahzadeh M, Sajadi SM (2020) Facile synthesis of $\mathrm{Ag} / \mathrm{ZrO} 2$ nanocomposite as a recyclable catalyst for the treatment of environmental pollutants. Compos B Eng 185:107783

16. Navratil J (1989) Ferrite use in metal recovery and waste processing. In: CHEMECA 89: technology for our third century; the seventeenth Australasian chemical engineering conference. Australasian chemical engineering conference, $\mathrm{p} 1000$

17. Navratil J (2001) Pre-analysis separation and concentration of actinides in groundwater using a magnetic filtration/sorption method I, Background and concept. J Radioanalyt Nucl Chem 248(3):571-574

18. Jaleh B, Khalilipour A, Habibi S, Niyaifar M, Nasrollahzadeh $M$ (2017) Synthesis, characterization, magnetic and catalytic properties of graphene oxide/ $/ \mathrm{Fe}_{3} \mathrm{O}_{4}$. J Mater Sci Mater Electron 28(6):4974-4983

19. Begum R, Najeeb J, Sattar A, Naseem K, Irfan A, Al-Sehemi AG, Farooqi ZH (2019) Chemical reduction of methylene blue in the presence of nanocatalysts: a critical review. Rev Chem Eng

20. Cullity BD (1956) Elements of X-ray diffraction. Addison-Wesley, Reading

21. Zhou S, Garnweitner G, Niederberger M, Antonietti M (2007) Dispersion behavior of zirconia nanocrystals and their surface functionalization with vinyl group-containing ligands. Langmuir 23(18):9178-9187

22. Muroi M, Street R, McCormick P, Amighian J (2001) Magnetic properties of ultrafine $\mathrm{MnFe}_{2} \mathrm{O}_{4}$ powders prepared by mechanochemical processing. Phys Rev B 63(18):184414

23. Tang I-M, Krishnamra N, Charoenphandhu N, Hoonsawat R, PonOn W (2011) Biomagnetic of apatite-coated cobalt ferrite: a coreshell particle for protein adsorption and $\mathrm{pH}$-controlled release. Nanoscale Res Lett 6(1):19

24. Ghosh BK, Hazra S, Naik B, Ghosh NN (2015) Preparation of Cu nanoparticle loaded SBA-15 and their excellent catalytic activity in reduction of variety of dyes. Powder Technol 269:371-378

25. Bordbar M, Negahdar N, Nasrollahzadeh M (2018) Melissa officinalis $\mathrm{L}$. leaf extract assisted green synthesis of $\mathrm{CuO} / \mathrm{ZnO}$ nanocomposite for the reduction of 4-nitrophenol and Rhodamine $\mathrm{B}$. Sep Purif Technol 191:295-300

26. Gan Z, Zhao A, Zhang M, Tao W, Guo H, Gao Q, Mao R, Liu E (2013) Controlled synthesis of Au-loaded $\mathrm{Fe}_{3} \mathrm{O}_{4} @ \mathrm{C}$ composite microspheres with superior SERS detection and catalytic degradation abilities for organic dyes. Dalton Trans 42(24):8597-8605

27. Liu Y, Zhang Y, Kou Q, Chen Y, Han D, Wang D, Lu Z, Chen L, Yang J, Xing S (2018) Eco-friendly seeded Fe 30 4-Ag nanocrystals: a new type of highly efficient and low cost catalyst for methylene blue reduction. RSC Adv 8(4):2209-2218

28. Amir M, Güner S, Yıldız A, Baykal A (2017) Magneto-optical and catalytic properties of $\mathrm{Fe}_{3} \mathrm{O}_{4} @ \mathrm{HA} @ A g$ magnetic nanocomposite. J Magn Magn Mater 421:462-471

29. Kurtan U, Amir M, Baykal A (2016) $\mathrm{Fe}_{3} \mathrm{O}_{4} @$ Nico-Ag magnetically recyclable nanocatalyst for azo dyes reduction. Appl Surf Sci 363:66-73

30. Ma X, Guo Y, Jin J, Zhao B, Song W (2017) Bi-functional reduced graphene oxide/AgCo composite nanosheets: an efficient catalyst and SERS substrate for monitoring the catalytic reactions. RSC Adv 7(67):41962-41969

31. Shah LA, Sayed M, Fayaz M, Bibi I, Nawaz M, Siddiq M (2017) Agloaded thermo-sensitive composite microgels for enhanced catalytic reduction of methylene blue. Nanotechnol Environ Eng 2(1):14

32. Ucar A, Findik M, Gubbuk IH, Kocak N, Bingol H (2017) Catalytic degradation of organic dye using reduced graphene oxide-polyoxometalate nanocomposite. Mater Chem Phys 196:21-28

33. Ali F, Khan SB, Kamal T, Alamry KA, Asiri AM, Sobahi TR (2017) Chitosan coated cotton cloth supported zero-valent nanoparticles: 
simple but economically viable, efficient and easily retrievable catalysts. Sci Rep 7(1):1-16

Publisher's Note Springer Nature remains neutral with regard to jurisdictional claims in published maps and institutional affiliations. 